\title{
Climate cosmopolitics and the possibilities for urban planning
}

\author{
Authors \\ Donna Houston (Department Geography and Planning, Macquarie University, \\ Sydney, Australia) \\ Diana MacCallum (Department of Planning and Geography, Curtin University, Perth, \\ Australia) \\ Wendy Steele (Global, Urban and Social Studies, RMIT, Melbourne) \\ Jason Byrne (Environment, Planning and Architecture, Griffith University, Gold \\ Coast, Australia).
}

\section{Corresponding author}

donna.houston@mq.edu.au

\section{Publication Details}

Paper accepted for a special issue of Nature + Culture 'Beyond Utopia, Crisis, Values and the Socialities of Nature'

\begin{abstract}
Cosmopolitical action in the climate-changed city represents different knowledges and practices that may seem disconnected but which constellate to frame stories and spaces of the climate-just city. The question this paper asks is: how might we as planners identify and develop counter-hegemonic praxes that enable us to re-imagine our experience of, and responses to, climate change? To explore this question, we draw on Isabelle Stengers' (2010) idea of cosmopolitics where diverse stories, perspectives, experiences and practices can connect to create grounding for new strategic possibilities. Our paper is empirically informed by conversations with actors from three Australian cities (Sydney, Brisbane and Perth) who are mobilising different approaches to this ideal in various grassroots actions on climate change.
\end{abstract}

Key words: Climate change, urban planning, cosmopolitics, Australia 


\section{Climate cosmopolitics and the possibilities for urban planning}

\section{Introduction}

Climate change sometimes figures as a site in which long-standing debates are re-enacted and sometimes as a problem the scale and character of which calls for really new ways of thinking. Meanwhile, climate change policy proceeds on the basis of an extraordinarily limited understanding of the social world and is, for the most part, untouched by theoretical debate of any kind at all. Elizabeth Shove 2010, p.278

Climate change is a messy policy issue in Australia. At the Federal level, the need to act has been accepted only relatively recently, and a fragile national agenda for mitigation and adaptation is slowly emerging. State and, especially, local governments have to various extents been developing their own approaches to the problem since the 1990s, often with help from international sources such as the International Council for Local Environmental Initiatives (Bulkeley 2001; Betsill and Bulkeley 2006; Gupta 2010). In spite of this fragmentation, there seems to be remarkable consistency between the published climate responses of different governments, including those promulgated through urban planning strategies. Almost all seem to draw on similarly neoliberal forms of governance, which propagate methods of risk management that collapse uneven geographies and ecosocial complexity into benchmarks and technical fixes (Rogers 2013). Recent enquiries suggest that very few approaches, if any, pay serious attention to social implications of climate change, including its potential impacts on equity, culture, democratic governance or multispecies relations (Byrne et al. 2009; MacCallum et al. 2011; Rice 2010). 
We are intrigued by this gap and its application within contemporary Australian urban planning knowledge and practice. We contend that current responses to climate change in Australian planning strategy represent a failure in material imagination: where the discursive segregation of social and ecological concerns from the environmental/economic imperatives of the climate change crisis impede action toward sustainable and just urban futures. We also contend that normative dimensions of urban climate change policy can only have limited purchase in grasping present eco-geo-social realities in contemporary cities.

Previously, we have argued for the need for an engaged, robust and material understanding of urban climate justice in planning that recognises: (i) that climate change is a crisis of society as well as environment, wherein the impacts are felt most by the most marginalised sectors of society (both human and non-human) not only at the global scale, but at within cities and suburbs as well; (ii) that society, economy and nature are all, simultaneously, mutually and constantly, reconfigured by the ways that urban relations are played out; and (iii) that as a result we must better take into account the complex links between human society and the natural environment, currently locked into processes that remain hardwired to spatial, temporal and economic models of growth that are not equitable, not eco-sensitive and not substantively oriented towards transitioning to low-carbon futures (Steele et al. 2012). Our discussion here further considers how urban planners might identify and develop counter-hegemonic discourses and praxes that enable us to re-imagine our experience of, and responses to climate change, in ways that support multispecies justice in the climate-changed city (Lorimer 2012). 
In this paper, we contend that "cosmopolitics" (Stengers 2010) is a materially imaginative exercise that moves beyond the technical and institutional "fixes" of climate change policy and strategy in Australian cities. Isabelle Stengers (2010) argues that cosmopolitics are constellations of diverse inhabitations - where human and nonhuman stories, relations, politics and practices can connect to destabilise the hegemony of technocratic responses to climate change. This paper explores the possibilities of cosmopolitics as a means for urban planning to rethink its "ethics of connection" (Rose and Robin 2004). Rethinking "ethics of connection" in urban planning draw on insights from the environmental humanities as well as recent social science research focused on material and creative practices of sustainable and just urban transitions (see Rose at al 2012; Gabrys 2013; Broto and Bulkeley 2013). We argue that exploring seemingly disparate types of community work around climate change highlights the spaces, places and practices whereby people reshape urban boundaries and connections in novel and surprising ways (Steele et al 2013). We conclude with the argument that planning systems need to take cosmopolitical constellations seriously if they to engage with the collective task of putting cities "together differently" in a climate-changed world (Gibson and Head 2012).

\section{Cosmopolitics: a different ethical-political imagination for urban planning}

A common world is not something we come to recognize, as though it had always been here (and we had not until now noticed it). A common world, if there is going to be one, is something we will have to build, tooth and nail, together. Bruno Latour 2010, p. 455 
The apparent domination of technical and neoliberal climate change policy might be seen as a realisation of what Shove (2010) calls the "mirror" of climate change - the tendency for urban researchers, policy makers, and planners to look at the "problem" of climate change and see their own values reflected back at them. In policy arenas we tend still to see a discipline, and disciplinary objectives, shaped by scientific norms, by a faith in technological progress and by universal conceptions of the public and the public good. In urban policy cycles, these normative epistemologies and/or goals underpin the formation of measurable standards that are used to govern and manage responses to extreme events and climate change in cities (Rogers 2013). Rogers (2013, p. 384) cautions that these unacknowledged normative dimensions of climate change policy can form "rigidity traps" that are built in to responses to urban climate change. "Rigidity traps" are contradictory policy formations, which make climate change adaption visible and intelligible to neoliberal policy and governance, while potentially increasing community vulnerability to climate change because they are not responsive to contingent local conditions or what falls through the gaps. The neoliberal fixation on standards and benchmarks in urban governance, for Rogers, is particularly worrying because of the tendency of measurable outcomes to become static: while fluid and relational factors based on other forms of interconnected knowledge and practice (for example, cultural memory, local experience, environmental and multispecies justice, bio-regional and geological imaginations) are ignored.

"Rigidity traps" in urban climate and disaster resilience policy legitimate that of which they speak. Four decades of social critique in urban and planning theory have 
emphasized the contingency, contentiousness and fragility of norms and social goods. Yet, when we imagine what planning looks like in the climate-changed city there appears to be disconnects between theories of contingency and practices of certainty. In theory, we accept "ontological pluralism" - that the world is understood and experienced differently by different social actors (Howitt and Suchet-Pearson 2003) and we understand that technology and knowledge are constructed in and mediated by practices that are themselves contingent. But in practice, we are often mired in performances of accountability that impede the development of substantively different urban policy. As the eco-social semiotician Jay Lemke (1993, p. 271) reminds us: "wherever there are meanings enabled there are also necessarily meanings disabled". Thus, when certain ways of speaking come to dominate public discourse, alternative voices are silenced, and alternative pathways become unimaginable.

Material and political life in the climate-changed city requires approaches to policy and practice that draw primarily upon recognizing and embracing connectivities as opposed to simply fixating around certainty. We argue that cosmopolitics can help urban planners to imagine what this looks like -and it is this re-imagining that is key. The idea of cosmopolitics that we are working with in this paper is inspired by Isabelle Stengers $(2005,2010)$ whose work on this theme questions Western scientific orderings and practices and which draws inspiration from attentiveness to generous political entanglements with the cosmos which is unknown and which cannot be brought into account through generalized procedures of the common good.. Cosmopolitics, thus, represent a way of thinking and doing that destabilises 
fixed notions of both the world (cosmos) and the political (Latour 2004). In challenging the privileged position of science in our repertoire of knowledge making, it extends the site of "politics" beyond a limited citizenry or polis, to include all actors - citizen, non-citizen; human, non-human; conscious, non-conscious - in the cosmos. At the same time, it honours the intangible - experiences, emotions, relationships, beliefs, practices - as essential moments of the "real", making the cosmos itself an object of continuous political negotiation between actors.

Cosmopolitics support "ecologies of practices", in which science, technique and technologies interact with other equally valid and important modes and products of action in ways that matter, in ways that shape the future (Stengers 2010). Cosmopolitics, as Stengers imagines them, thus represent modes of disentangling politics from "postpolitical" consensus (2005). Cosmopolitics resist the legitimization of consensual knowledge that offer "protections" to universalising ways of seeing and doing and which affirm the status quo in the name of emergency (2005). For Stengers, cosmopolitics is an invocation to "think in the presence of" - as this profoundly reshapes the questions we ask of the present in ways that leave "no-one unaffected" (Stengers 2005, p. 1002). To "think in the presence of" distinguishes between working with "detached" knowledge and working with "relevant" knowledge - so it does not reject science or policy but it does call into question they actually do as a means of developing practical, situational politics in emergent and unknowable conditions. In this sense, Stengers argues, that cosmopolitics prompts "us to consider this world with other questions, to disregard watchwords that present it as ‘approximately normal'” (2005, p. 998). 
Stengers' cosmopolitics are different to cosmopolitanism (Beck 2006) and cosmopolis (Sandercock 1993, 2003), which are two concepts that are more familiar to urban planning theory. Cosmopolitanism is often evoked by urban scholars to represent democratic values and practices that celebrate mobility and diversity, but it has been problematized for its privileging of uncritical notions of "common grounds" (dissolving borders, overcoming barriers as global citizens) as the way forward (cf. Our Common Future, the Brundtland report WCED 1987). Such ideals often limit capacities to politically recognise or redress the "banal geographical evils" and persistent injustices of global capitalism and uneven development (Harvey 2000). Similarly, the search for common space in cosmopolitan thinking also produces "failing universalisms" because they privilege Western ontological perspectives on what it means to be human in the world (Di Chiro 2008; Blok 2011). Both critiques of cosmopolitanism call for greater attention to be placed on the politics of who benefits from cosmopolitan ideals and the ways they can foreclose on sustainable and just alternative futures (Blok 2011).

Conversely, Cosmopolis promoted by Leonie Sandercock (1998; 2003), is a cosmopolitan utopia in which difference and mutual interdependence are the basis for societal norms, in which communities of difference are given space to define and articulate their own needs, and in which traditional, rationalistic modes of planning are supplanted by more fragmented, communicative, creative and openly principled practices. These norms make explicit the need for a cosmopolitanism that addresses the problems noted above, and have provided fertile grounds for theorizing the possibilities of urban encounter by being attentive to the basic 
eccentricities of urban life: it strangeness, differences and connections (Fincher and Jacobs 1998).

This understanding of cosmopolis as representing hybrid "mongrel" politics open to contingencies, differences and uncertainties is much closer to the cosmopolitics imagined by Latour and Stengers. Yet, as Gill Valentine $(2008,324)$ observes: "Much of the writing that is associated with what might be regarded as a "cosmopolitan turn" in thinking about the city celebrates the potential for the forging of new hybrid cultures and ways of living together with difference but without actually spelling out how this is being, or might be achieved in practice." Moreover, cosmopolitical writing around cities has tended to enact a kind of human-centred closure around the polis.

In sum, cosmopolitical theory has been utilised by planners (and planning scholars) within city contexts to promote socially diverse, liveable urban spaces. However, there has been far less emphasis on the cosmopolitics inspired by Stengers, which consider how we "live together" in cities with other species and other inhuman geophysical agents (Clark, 2010; Steele and Vizel 2013). Urban planning systems, along with other "expert designs" of capital, science and the state have ignored and undermined the heterogeneous ecologies of cities and our political responsibilities toward them (Hinchcliffe et al 2006, p. 124). Urban cosmopolitics thus compel us to enlarge our understandings of urban encounter, civic culture, liveability, survivability and justice to encompass "more-than-human" relations as a "cause for thinking" (Stengers 2005, p.1002). 


\section{Climate cosmopolitics as alternative urbanisms}

The ecological genius of cities remains a vast, largely hidden power. Mike Davis (2010, p. 43)

Cities are multinatural places, but strategic planning processes often work against ecological connectivities because they are fundamentally driven by practices that divide and demarcate particular land uses from each other, define social and political borders between communities, and privilege capital growth as the force that sustains urban life (Steele et al 2013; Lorimer 2012). But in an era of climate change and economic uncertainty, the stability and viability of decisions that facilitate short-term economic growth over longer-term ecological and socioeconomic viability have been called into question. Cosmopolitical projects in the climate-changed city are not just about planning for a future that is impossible to predict, nor about including "stakeholders" in processes that may or may not engage them. Rather, they call to our attention how unlike practices - of policymaking, everyday life, and ecological interactions - continuously impinge upon each other. Cosmopolitics in the climate-changed city do not disavow the politics of urban placemaking - but they do transform them into something that is less concerned with final solutions, less inclined to reproduce "rigidity traps" through established techniques and technologies (Rogers 2013, Gabrys 2013). In what follows, we present a small taste of the community work that is going on in our home cities in Australia. These projects are not unusual in the world but when they are brought into cosmopolitical proximity they represent collective efforts to bear witness to the effects of climate change, to (re)imagine its meanings, to decouple urban experiences from 
hegemonic discourses and practices, and to enact different urban and multispecies possibilities.

(i) Sydney: Synurbic species and witnessing climate change

In the climate-changed city, multispecies relationships can become all the more fraught as environmental pressures in rural and regional areas (fire, drought, land clearing) means that other species are becoming increasingly dependent on urban areas for survival. In Sydney, the Australian White Ibis (Threskiornis molucca) is a native species that has become increasingly prevalent in urban areas over the past three decades (from several breeding pairs reportedly released by Toronga Zoo in the 1970 s to a population of approximately 7000 birds). The lbis might be an example of what Francis and Chadwick (2011) call "synurbic species" - species that are increasingly associated with urbanization, and which are in turn changing behaviour (nesting, foraging, breeding) and biology in complex and unpredictable ways. Although they are protected under the National Parks and Wildlife Act (1974), Ibis are not universally loved birds in Sydney. For many people, the Ibis are considered pests because they are associated with rubbish and landfills (which contain readily available sources of fast food) and because they are highly social birds that tend to congregate in large colonies that are noisy and smelly. Ibis also pose a strike risk when they nest in marshlands near the Sydney international and domestic airports.

Ibis have a range of up to $25 \mathrm{~km}$ a day and do not distinguish between boundaries of private and public property, so their nesting and foraging behaviour pose a particular 11 
challenge for urban and environmental planners. In Sydney, several local government areas have produced Ibis Management Plans that demonstrate a range of responses and strategies. For the most part, the lbis are treated as an "overabundant" problem that can be managed through habitat modification, the removal of nesting material and food sources, the removal of nests and eggs, noise deterrence and in some instances through culling and shooting (Management Plan for Australian White Ibis in the Bankstown Local Government Area 2004). While Ibis are highly visible birds in Sydney's urban spaces, their ubiquitousness also masks the fact that little is known about their urban ecology and their future survival trajectories on a continental scale (Martin et al 2012). The massive decline of Ibis in their traditional inland breeding areas means that their futures are increasingly entangled in urban decision making processes and it means that places like urban landfills and weedy marshlands have become "incidental wildernesses" crucial to sustaining Ibis populations.

The urban governance of wildlife is broadly concerned with multiscaled connectivities - but in practice - different levels of government often produce contradictory narratives, practices and visions of how different species are managed within the city. For example, at the local government level lbis management is connected to local land-use issues and conflicts, so the boundary placed around them is often an act of containment (managing populations, destroying nests, dispersing birds to other wetlands locations, etc.) or defined by spatial boundaries between local government areas, public and private property, etc. The management of lbis at the local level is rarely seen as an indicator of environmental change 
occurring at bioregional or continental scales, nor do such approaches readily recognise that managing Ibis populations in situ might be contributing to the Ibis' overall decline. This is particularly evident in the focus on nesting and breeding sites in local lbis management plans - where the destruction lbis places within the city ignores the fidelity that the birds have towards particular places and assumes that mobile avian fauna has the capacity to "move-on" even as the pressures of urban development and wetland loss mean that that there might not be anywhere else to go. Such practices also assume the Ibis as incapable of "storying" their own multispecies places in the city and render them meaningful (van Dooren and Rose 2012).

In 2006 the NSW Department of Environment and Climate Change (now the Office of Environment \& Heritage) produced a booklet called "Wild About lbis: Living with Urban Wildlife", which made explicit the connections between urban Ibis, behaviour and ecology, and the health and integrity of wetlands in inland areas. The "Wild About Ibis" booklet was intended for a wider public audience than the Ibis management plans produced for local governments, but it nonetheless interrupts certain ways of seeing and practicing Ibis management in the city. In particular, the "Wild About Ibis" booklet emphasised the cultural and ecological significance of Australian wetland birds and their ability to adapt to harsh environments. The booklet also noted a significant decline in lbis observed in their traditional breeding sites in Lake Macquarie - noting that urban areas are critical for nurturing current breeding populations. 
What is often missing from efforts to understand Ibis in contemporary Australian urban governance and planning imaginaries is precisely an exercise of "thinking in the presence of" outlined by Stengers (2005). "Thinking in the presence of" incorporates science, urban planning and wildlife management issues - but this is not a one-way street where the lbis simply become objects of urban governance. Thinking in the presence of the lbis, highlights a set of political and ecological responsibilities involved in witnessing climate change and the slippery slope of many Australian species towards extinction, but it is an invocation to situate the city and the ways in which is governed in "ecological terms" (Plumwood 1993). "Thinking in the presence of" is therefore not the same as "thinking like" - though such exercises in enlarged thinking are useful for framing more-than-human interactions with what many consider a pest species. Rather the cosmopolitical goal is articulate how the Ibis are "climate witnesses" and how their future trajectory is entangled in complex regional political ecologies that call into account the technologies, techniques and practices that impinge upon their survival.

The point of cosmopolitical approaches is to explore how scientific research works in conjunction with other forms of knowledge and activities that make it possible for other forms of connections to emerge (Whatmore and Landström 2011; Gabrys 2013). In this sense, Ibis are climate witnesses but are also witnessed by individuals and the groups who care for them. Since 2003 local community members throughout urban and regional NSW have participated in the lbis Community Survey - a citizen science project organised by NSW Environment \& Heritage to better understand these broader connectivities and consequences. 
Citizen science projects is a useful tool for urban planning because it can yield accurate observational data across temporal and geographical scales - as ordinary people are able to observe Ibis in everyday and often hard-to-reach places and log this information onto an online survey. Citizen science is also an educational practice, which brings the scientific techniques of lbis management into public view and with it different possibilities for understanding the ecological city.

Indeed, the lbis survey draws attention to the role of citizen science as one type of cosmopolitical constellation, where people draw on observations of a range of climate change proxies: recording (in various modes) weather patterns; telling stories and chatting about the weather; preparing for drought or flood; documenting field observations of ecological indicator species; replacing water-hungry gardens with "water-wise" ones, raising frogs, watering urban birds and supporting urban wildlife and species migrations. Citizen science projects are an increasingly important tool in wildlife conservation because non-expert citizens can collect highquality data and observations from hard to reach places (such as suburban back gardens); but they remain an under-utilized tool for understanding climate-change in urban planning contexts.

\section{(ii) Brisbane: Re-imagining food sovereignty}

Seasonal and everyday multinatural relationships in the city involving human and non-human are also realised through connections to food and livelihood providing new insights for how planning could be done differently in a climate-changed city. 
In Brisbane (QId) a number of different re-imaginings are currently being enacted at the grass-roots level around the notion of food - not as some futuristic climate change agenda - but as a series of creative ways of re-thinking food sovereignty firmly planted [sic] in the here and now. For example within the inner-city Brisbane suburb of West End a number of alternative grassroots food-related projects exist proffering quite a different set of ideals to mainstream hegemonic ones. This is expressed through a range of diverse activities that seek to address issues of food access, choice, creation, supply, diversity and management. These include:

- A small volunteer co-operative of local residents who offer - for free local food tours of the West End area highlighting the fruits, herbs and other delicious edibles that are available (depending on the season) throughout the suburb as a means of expanding community food knowledge and networks.

- A West End activist collective has taken steps to go around and harvest ripened fruit from local trees (avocados, oranges, mangoes, passionfruit, bananas etc.) - making them freely available to all rather than seeing the fruit rot on the tree or the ground as an explicit protest against food waste.

- Individual activists regularly engage in 'dumpster diving' to retrieve some of the vast quantities of food that is thrown out on a daily basis by large companies in compliance with health and other regulations, but that are still edible and able to be used in creative ways. 
- Guerrilla plantings occur on sidewalks as a way of reclaiming public space for fruit, vegetables, flowers and other food producing and community purposes.

These diverse stories and practices work as cosmopolitical projects to destabilise the way issues of food are understood and practiced, disrupting in particular the conventional top-down, technocratic and managerial approaches to nutritious and affordable food. In Australia this has emerged through government initiatives such as the National Food Plan (NFP), which emphasizes a corporate approach to food aimed at the 'big end of town'.

Rather than accepting this national food proposal, activist organisations in Brisbane and across Australia have united to develop the 'Peoples Food Plan'. Their collective agenda is 'visionary and transformative change' that builds towards "establishing a more coherent and cohesive food justice / fair food movement around the country" rather than "a business-as-usual plan to suit the needs of big agri-business, major retailers and commodity exporters" (Australian Food Sovereignty Alliance 2012, p.1).

(iii) Perth: Ecoburbia, an exercise in resilience

We contend that cosmopolitical practices help to disturb many of the conventional boundaries between economic, social and environmental action. In Perth (WA), for example Ecoburbia is an enterprise that is both a business and a community, oriented to building resilience and creating sites for cooperation and learning at both 17 
the neighbourhood and metropolitan scales. The mainstay of the business side is that its owners, Shani and Tim, run regular training sessions for Perth's "Living Smart" program, an initiative to help (mostly) householders to adopt goals and actions for a sustainable lifestyle. ${ }^{1}$ However, as an independent company with a large social and professional network, they can also be quickly responsive to ad hoc opportunities as they arise - hosting a small conference with an international guest, facilitating local distribution of solar panels and engaging in community education.

Of particular interest is the work going on at Hulbert St Fremantle, where Shani and Tim live. Shani describes Hulbert St as an 'unintentional community', the outcome of various decisions of its residents to live in a certain way or, in their case, to develop a property up the street from their home, which serendipitously led to their getting to know all their neighbours. Here are some of the things that Ecoburbia does here, tacitly but mostly not formally supported by the local government ${ }^{2}$ :

1 Living Smart was created in 2003 as a fairly informal partnership between Murdoch University, the City of Fremantle, the Meeting Place community centre (Fremantle) and the Southern Metropolitan Regional Council. In 2011 it became an independently incorporated not-for-profit organisation. 'Graduates' of the Living Smart training may join the 'Living Smarties' network; members regularly meet to share concerns, goal setting and skills, from energy-efficient construction to water purification, financial management, permaculture, food processing, making household and personal hygiene products, sewing, etc. They can be found on the web at: http://ecoburbia.com.au/

${ }^{2}$ Which, for instance, turns a blind eye to the closure of the street for the festival and the use of common land for gardening and small-scale infrastructure. 
- Maintains a 'community assets inventory' of the sharable skills (electrician, teacher, knows how to pickle fruit, etc.) and tools (ladder, sewing machine, trailer) for residents.

- Establishes local food gardens and, in small ways, collectivises the costs of water use to support these.

- Holds a monthly film and discussion night on the street, open and free to everyone.

- Organises an annual 'sustainability fiesta' for the promotion of community actions, local produce, arts and crafts, and 'environmentally friendly' products (the vision, as they put it being to 'educate and inspire').

- Invests profits from the fiesta into communally owned useful things (a mobile pizza oven, an olive press).

We can see these interlinked practices as taking place in a cosmopolitical space that brings together the histories and experiences (for example as manifest in the skills and knowledge they share) of a culturally and socio-economically diverse group of people - not all of whom believe in the twin spectres of climate change and peak oil, but all of whom care about the welfare of their neighbours and the future of their street. Hulbert Street represents a somewhat under-acknowledged form of collective action - dependent neither on government funding nor on any 'shared vision', but on the affective and practical elements of good will and communication.

\section{Climate cosmopolitics in practice}


It may seem rather grandiose to talk about these small-scale local actions as 'cosmopolitical' - after all, their reach is hardly cosmic. How do these case studies and practices alter human-nature relations, and actors' intentionality? We believe that these relationships of local human-nature action in, with and to a climatechanged city, provide insights into alternative ways of thinking about how planners and planning systems can engage with the public ecologies of climate-changed cities.

The stories we have presented highlight, in manifestly present ways, changing imaginaries and practices in relation to knowledge production, personal and collective responsibilities, community development and urban living. They bring into proximity different modes and methods for working across different forms of material change in cities. Ecoburbia for example speaks of the possibility of collective commitment and action without collective vision. This is an anathema to the principles of the New Public Management, but an achievement that may be necessary in the face of the climate change crisis - globally dispersed, unevenly harmful and ontologically precarious. Conventional strategic planning, so often framed in relation to 'shared' aims and objectives (MacCallum 2008), can be paralysed by ongoing disagreement over the nature of such problems, as we have seen (Innes and Booher 2010). But perhaps climate cosmopolitics can also serve as a form of memory-work too, where planners, artists, designers, educators, workers, activists can call upon the radical urban traditions of communal ethos and enlarge them (Davis 2010, p.42). 
The cases outlined above help to express people's experience of, and reaction to, climate change and other crises; they challenge the felt disjunct between actors' (including actors such as planners, developers, politicians, lobbyists) professional and personal identities. In doing so they start the process of reconfiguring eco-social relations, recontextualising climate discourses, and producing new modes of enactment. As part of the 'Peoples' Food Plan, kitchen-table style conversations are being held locally and nationally in response to the official consultation process. These include performance and speaking events as well as the active engagement of social and other media around alternative food visions. In Australian cities such as Brisbane this is a potentially powerful way of inserting these ideas within mainstream urban policy and planning processes via grassroots climate movements that challenge and disrupt mainstream climate politics, thereby rendering them visible.

For climate change is often difficult to see in an everyday sense, particularly in the cities of developed countries like Australia. Michael Hulme (2010) observes that the climate (and natural systems more generally) is now neither natural nor anthropogenic, but a kind of hybrid (Crutzen and Stoermer 2000; Zalasiewicz et al. 2010). There can be no certainty as to whether particular weather or extinction events, for example, have their origins in the human production of carbon emissions. How, then, do urban citizens know climate change and how do they make climate manifest (Slocum 2004; Clarke 2010)? One answer to this question comes from ethnographic and storied explorations of ecology, time and place in the city. Everyday interactions between people and nonhuman others in urban contexts are 21 
characterized by affective and corporeal entanglements - where feelings of joy, despair, hope and vilification play out in daily encounters, and in urban politics and spaces.

There are few artificial dichotomies here between personal and community resilience; nor between mitigation and adaptation in relation to crisis. Indeed, climate change itself does not seem to be generally understood as a separate object, but as one element (along with local embeddedness in global economic events, disconnection from nature, perceived corruption of political processes, peak oil, social isolation, and many other things) contributing to a sense of "not-rightness" and vulnerability within parts of the community. This absence of reductionist analysis does not prevent coherent action - quite to the contrary, it enables people to work together on their general discomfort, without having to commit to particular values and beliefs (for example, in collective ownership of property, or anthropogenic climate change) that they do not share.

\section{Conclusion: the possibilities for urban planning}

We are at a time when planning's nature - though not its precise position - as part of an "ecology of practices" is particularly exposed. The uneasy relationship between the science and politics of climate change and the mandate of public policy to connect expertise, community aspirations and strategic decision-making, places difficult and often contradictory demands on policy makers. At this time, the illusion of "consensus" in relation to urban development (or, more generally, to practical 
action in the social/economic/environmental nexus) has well and truly foundered, leaving a gap in which a range of discourses and practices struggle for power. While the urgency of the climate change challenge often seems to work against widespread dialogue at the State level (MacCallum et al. 2011), this lack of consensus surely provides an opportunity to reimagine conditions for urban intervention. What possibilities might a cosmopolitical approach, attentive to such practices as we describe above, suggest for planning theory and practice? A few points come to mind.

The first point is that urban planning in Australia is in need of a re-enchantment with an ethics of connection - where temporal and spatial rhythms of seasons, floods, mosquitoes, bats, food, labour and mobility are integrated into the civic ecological design of cities. This requires both structural changes to the way in which cities prioritize privatised forms of economic development over collective "more-thanhuman" interests and genuinely common goods. This also means that planners need to be able to practice experimental politics that work to engage urban-publicecological configurations that support the kinds of resilience that are necessary for the future of the city. Such practices recognise that in the climate-just and cosmopolitical city the work of pollinators ought to be considered vital to production of urban space. Our point here is not to collapse different forms of local and global injustice into a "flat ontology" of human and non-human networks, but rather, to reorient how the imaginative political work of cities is reconfigured through climaterelated practices that constellate into publically discernable and actionable phenomena. 
Mike Davis $(2010$, p. 45$)$ recently wrote that: “...to raise our imaginations to the challenge of the Anthropocene, we must be able to envision alternative configurations of agents, practices and social relations, and this requires in turn, that we suspend the politico-economic assumptions that chain us to the present." Cosmopolitics exposes relations between knowledge, practice and identity, upsetting the boundaries that we - as urban planners, say - place between different moments and aspects of our existence. The affective and ideological impulses behind personal choices - to install solar panels, to attend a street party, to decline to keep a cat, to grow vegetables, to walk to work, to make our own birthday cards, to move to a higher density neighbourhood, or not, for example - cannot readily be untangled from our professional/scientific knowledge of the issues; nor can they be kept out of our thinking on policy directions. Each of us is a peculiar bundle of identities, whose decisions about how to live our own lives impinge on those about how other people should/will live theirs. Seeing professional planning ethics in the context of an ecology of practices forces us to acknowledge this. In acknowledging these relationships, we might be better equipped to see the potentialities inherent in the tensions that they produce.

We believe that the current policy gap between the two imperatives of climate change response and urban eco-social justice can only be bridged by finding radically new ways of doing policy and planning. By paying attention to these alternative stories, we can begin to see how intangible and embodied interactions between imagination and knowledge, between human and non-human, between experience, desire and action - work to shape and sustain city life in a context of 
environmental crisis. This is the essence of cosmopolitics as action - to change the social/political/natural world by changing how we live with it. 


\section{References}

Beck, U. 2007. The cosmopolitan vision, Cambridge, Polity Press.

Betsill, M. and Bulkeley, H. (2006) Cities and the multilevel governance of global climate change Global Governance 12: 141-59.

Blok, A. (2011) War of the Whales: Post-Sovereign Science and Agonistic Cosmopolitics in Japanese-Global Whaling Assemblages. Science Technology Human Values 36(1): 55-81

Broto, V. C., and Bulkeley, H (2013) Maintaining Climate Change Experiments: Urban Political Ecology and the Everyday Reconfiguration of Urban Infrastructure. International Journal of Urban and Regional Research. 6: 1943-1948.

Bulkeley, H. (2001) Governing climate change: the politics of risk society? Transactions of the Institute of British Geographers 26: 430-47.

Byrne, J., Gleeson, B., Howes, M. \& Steele, W. (2009) 'Climate change and Australian urban resilience: the limits of ecological modernization as an adaptive strategy', in Davoudi, S., Crawford, J. \& Mehmood, A. (eds.), Planning for climate change: strategies for mitigation and adaptation for spatial planners. London, Earthscan: 136-54.

Callon, M., Law, J. and Rip, A. (1986) 'How to Study the Force of Science' in Callon, M., Law, J. and Rip, A., eds., Mapping the Dynamics of Science and Technology: Sociology of Science in the Real World, London: MacMillan Press, 3-18

Clark, N. (2010) 'Volatile worlds, vulnerable bodies.' Theory, Culture \& Society 27: 31-53.

Crutzen, P. J., and Stoermer,E. F. (2000). The 'Anthropocene'. Global Change Newsletter 41: 17-18.

Davis, M. (2010) Who Will Build the Ark? New Left Review 61 (Jan-Feb): 29-46.

Di Chiro, G (2008) Living environmentalisms: coalition politics, social reproduction and environmental justice. Environmental Politics 17(2): 276-298. 
Fincher, R. and Jacobs, J.M, Eds. 1998 Cities of Difference. New York and London: the Guildford Press.

Francis, R. and Chadwick, M (2011) What Makes A Species Synurbic? Applied Geography 32: 514-521.

Gasper, R., Blohm, A. \& Ruth, M. (2011) 'Social and economic aspects of climate change on the urban environment', Current Opinion in Environmental Sustainability 3, 150-57.

Head, L. and Gibson, C. (2012) Becoming differently modern: Geographic contributions to a generative climate politics. Progress in Human Geography 36(6): 699-714.

Howitt, R and Suchet-Pearson, S (2003) Ontological pluralism in contested cultural landscapes in Anderson K., Domosh M., Pile S. and Thrift N. (eds) Handbook of Cultural Geography. London, Sage Publications: pp. 557-569.

Gabyrs, J. (2013) A Cosmopolitics of Energy: Diverging Materialities and Hesitating Practices (submitted to Environment and Planning A, accepted May 2013).

Gupta, J. (2010) A history of international climate change policy, Wiley Interdisciplinary Reviews: Climate Change 1, 635-653.

Harvey, D. (2000) Cosmopolitanism and the Banality of Geographical Evils. Public Culture 12(2): 529-564.

Hillier, J. (2007) Stretching Beyond the Horizon: A Multiplanar Theory of Spatial Planning and Governance, Aldershot: Ashgate

Hinchcliffe, S. and Whatmore, S. (2006) Living Cities: Towards a Politics of Conviviality. Science as Culture 15(2): 123-138.

Hinchcliffe, S., Kearnes, M., Degen, M., Whatmore, S. (2005) Urban wild things: a cosmopolitical experiment. Environment and Planning D: Society and Space 23: 643-658. 
Hulme, M. (2010) Cosmopolitan climates: hybridity, foresight and meaning, Theory, culture and society, 27(2): 267-276.

Innes, J. and Booher, D. (2010) Planning with Complexity, London: Routledge.

Kelly, P. and Adger, W. (2000) 'Theory and practice in assessing vulnerability to climate change and facilitating adaptation', Climate Change 47, 325-52.

Latour, B. (2004) Whose Cosmos, Which Cosmopolitics? Comments on the Peace Terms of Ulrich Beck. Common Knowledge 10(3): 450-462.

Latour, B. (2010) An Attempt at a Compositionist Manifesto. New Literary History 41:471-490.

Law, J., ed. (1986) Power, Action and Belief: A New Sociology of Knowledge? London: Routledge and Kegan Paul.

Lemke, J. (1993) 'Discourse, Dynamics, and Social Change', Cultural Dynamics, 6(1), 243-275

Lorimer, J. 2012 Multinatural Geographies for the Anthropocene. Progress in Human Geography. 36(5): 593-612.

MacCallum, D., Steele, W., Byrne, J., Houston, D., (2011) Environmental Imaginaries: climate change as an object of urban governance. State of Australian Cities, Melbourne, MU.

http://soac2011.com.au/files/papers/SOAC2011_0019_final.pdf.

Martin, J.M., French, K., Ross, G. R., Major, R.E. (2011) Foraging distances and habitat preferences of a recent urban coloniser: The Australian white ibis.

Landscape and Urban Planning 102: 65-72.

Plumwood, V. (1993) Feminism and the Mastery of Nature. Routledge: London and New York.

Rice, J. (2010) Climate, Carbon, and Territory: Greenhouse Gas Mitigation in Seattle, Washington. Annals of the Association of American Geographers 100(4): 929-937 
Rogers, P. (2013) The Rigidity Trap in Global Resilience: Neoliberalisation through principles, standards, benchmarks. Globalizations 10(3): 383-396.

Rose, D.B., van Dooren, T., Chrulew, M., Cooke, S., Kearnes, M, and O'Gorman, E. (2012) Thinking Through the Environment: Unsettling the Humanities.

Environmental Humanities 1: 1-5.

Rose, D.B. and Robin, L. (2004) The Ecological Humanities: An Invitation.

Australian Humanities Review 31-32 (Online:

http://www.australianhumanitiesreview.org/archive/lssue-April-2004/rose.html)

Sandercock, L. (1998) Towards Cosmopolis: Planning for Multicultural Cities,

Chichester: John Wiley

Sandercock, L. (2003) Cosmopolis II: Mongrel Cities in the 21st Century, London: Continuum

Scott-Cato, M. and Hillier, J. (2010) How Could we Study Climate-Related Social Innovation? Applying Deleuzean Philosophy to the Transition Towns, Environmental Politics 19(6): 869-887

Sherrard, J. \& Tate, A. (2007) 'Equity in response to climate change roundtable: An Australian snapshot', in Brotherhood of St Laurence (ed.), Equity in Response to Climate Change. Roundtable Report. Melbourne: 24-35.

Shove, E. (2010) Social theory and climate change: Questions often, sometimes and not yet asked, Theory, Culture \& Society 27(2-3): 277-288.

Slocum R. (2004) Polar bears and energy-efficient lightbulbs: strategies to bring climate change home. Environment and Planning D 22: 413-438.

Steele, W and Vizel, I. (2013) Housing and the Material Imagination - Earth, Fire, Air and Water. Housing Theory and Society (ahead of print)

Steele, W., MacCallum, D., Byrne, J., Houston, D. (2012) Planning the climate-just city, International Planning Studies 17(1): 67-83. 
Steele, W., Alizadeh, T., Eslami-Andargoli (2013) Planning Across Borders.

Australian Planner 50(2): 96-102.

Stengers, I (2005) The Cosmopolitical Proposal. In B Latour and P Weibel (eds) Making Things Public: Atmospheres of Democracy. Cambridge MA: MIT Press, pp: 994-1003.

Stengers, I. (2010/1996) Cosmopolitics I, II. Translated by Robert Bononno. Minneapolis: University of Minnesota Press.

Van Dooren, T and Rose, D.B., (2012) Storied-places in a multispecies city. Humanimala: a journal of human/animal interface studies. 3(2): 1-27.

WCED (1987) Our Common Future, Oxford: OUP.

Whatmore, S.J. and Landstrom, C. (2011) Flood apprentices: an exercise in making things public. Economy \& Society 40(4): 582-610.

Yusoff, K. and Gabrys, J. (2011) Climate change and the imagination, WIREs climate change 2: 516-534.

Valentine, G. (2008) Living with Difference: Reflections on Geographies of Encounter. Progress in Human Geography 32(3): 323-337.

Zalasiewicz, J., Williams, M., Steffen, W. and Crutzen, P. (2010) The New World of the Anthropocene, Environmental Science and Technology 44 (7): 2228-2231. 